Article type : Empirical Article
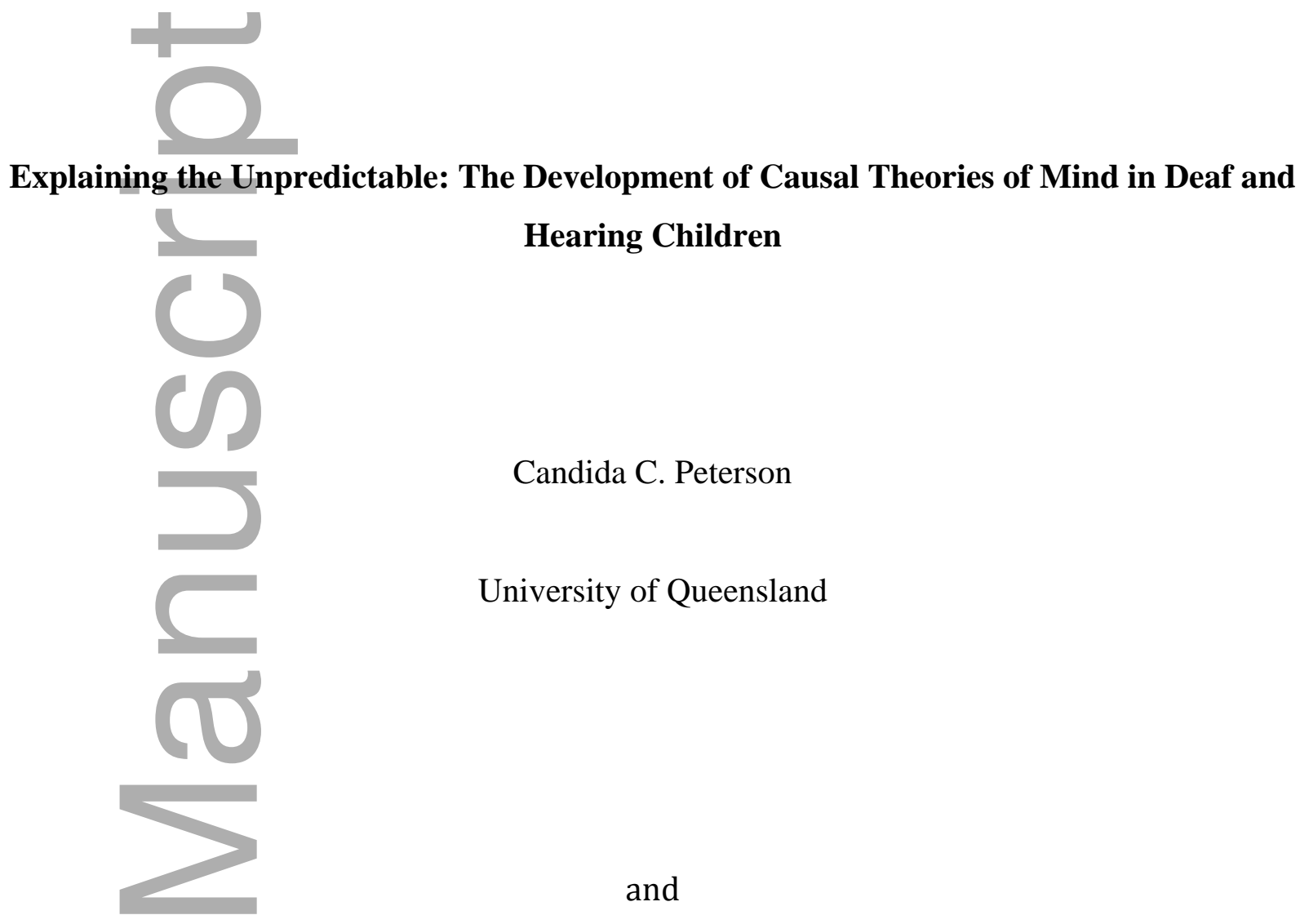

\author{
Candida C. Peterson
}

University of Queensland

and

Henry M. Wellman

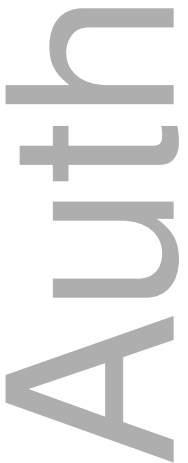

University of Michigan

This is the author manuscript accepted for publication and has undergone full peer review but has not been through the copyediting, typesetting, pagination and proofreading process, which may lead to differences between this version and the Version of Record. Please cite this article as doi: $\underline{10.1111 / c d e v .13092}$

This article is protected by copyright. All rights reserved 


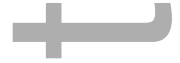

* Corresponding Author:

Professor Candida C. Peterson, School of Psychology,

University of Queensland, Brisbane, Queensland, Australia 4072

email: candi@psy.uq.edu.au; fax: 617-3365-4466.
\end{abstract}

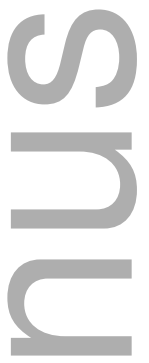

Abstract

Two studies of 100 children aged 3 to 12 years examined theory of mind (ToM) understanding via explanations and predictions in hearing preschoolers and ToM-delayed deaf children. Study 1's 75 children (31 deaf; 44 hearing) displayed an "explanation advantage", devising valid epistemic ToM explanations despite failing simpler forced-choice false-belief (FB) prediction tests. This novel discovery for deaf children extended to unexpectedly frequent cognitive ("think" or "know") explanations. Study 2 (with 25 additional deaf children; mean age 9) showed that microgenetic FB explanation practice resulted in significant gains on FB prediction post-tests that were absent in a non-ToM control group. Implications for (a) explanation's interconnection with conceptual development, (b) designing ToM interventions, and (c) teaching deaf and hearing children are discussed.

\title{
Explaining the Unpredictable: The Development of Causal Theories of Mind in Deaf and
}

\section{Hearing Children}

Explanation is fundamental to cognition and a natural part of everyday social interaction (Keil, 2006). When A asks "Why?" and B supplies an explanation, both parties are able to evaluate and learn about causal concepts. Why-questions are evident in children's spontaneous speech from as early as age 2 years (Hickling \& Wellman, 2001) and their focus, like that of children's explanatory answers, is most frequently on people's actions, desires, and beliefs (e.g., Callanan \& Oakes, 1992; 
Hickling \& Wellman, 2001). Children's own spontaneous explanations likewise draw heavily on themes of human behavior, emotion and belief (e.g., Dunn \& Brown, 1993). Schult and Wellman (1997) found young preschoolers explained people's mistaken actions (A wanted to do X but did Y) via psychological states over $85 \%$ of the time. Thus, children's causal questions and explanations reflect their developing theories of mind. Moreover, in both spontaneous conversation and in controlled laboratory tests, children's explanations are often surprisingly adept (Wellman, 2011). Hearing preschoolers often do better at explanation than prediction consistent with an "explanation advantage" hypothesis (Amsterlaw \& Wellman, 2006; Rhodes \& Wellman, 2013). Theory of mind (ToM), or the child's understanding of the mental world (Flavell, 2004) develops rapidly during childhood (Harris, 2006; Hughes, 2016; Wellman, 2014). One key aspect, the recognition that human behavior is the product of mental states like beliefs, is prototypically assessed using inferential falsebelief tasks (Wellman, Cross \& Watson, 2001).

There can be limitations to using tasks with a specific conceptual focus (e.g. false belief)) as a marker for a larger multi-faceted conceptual domain (e.g., ToM), as has been noted by several critics (e.g., Astington, 2001; Wellman \& Liu, 2004). For some purposes, however, a focus on false belief remains useful because such tasks (a) have been used and validated worldwide with thousands of children (see Wellman, et al., 2001, for a meta-analysis), (b) are consistently reliable in multiple variations (e.g., yielding the same results with dolls versus real people as protagonists: Wellman et al., 2001), and (c) have proved to reveal developmental change in both typically developing children (TD) and those with ToM delays owing to autism or deafness (see Happé, 1995, and Peterson, 2009, for reviews). Moreover, variation in false belief competence reliably predicts various socialinteractive competencies such as peer interactions, reciprocated friendship and popularity (see Slaughter, Imuta, Peterson \& Henry, 2015 for a meta-analysis), children's engagement in pretending and deception games (LaLonde \& Chandler, 1995; Peskin \& Ardino, 2003) or persuasion (Bartsch \& London, 2000; Slaughter, Peterson \& Moore, 2013), as well as academic achievement and relationships with teachers during the transition to school (Lecce, Caputi \& Hughes, 2011).

False-belief tasks, the prime measure of children's ToM in past research, usually require predictions of the actions or thoughts of naïve protagonists with beliefs that clash with reality. Most typically-developing (TD) children under age 5 fail by making reality-driven predictions that ignore the protagonist's state of mind. Another less common false-belief task, however, involves false belief explanation. As in prediction tasks, a naïve protagonist lacks information known to the child. Then the protagonist acts misguidedly (e.g., searches for an object where she last saw it rather than where it is now) and the child has to explain why. Strikingly, in direct comparisons, young children who do not yet fully understand false beliefs often perform better on explanation than prediction versions of the test. Children's superior performance on false belief explanation tasks is provocative because, on 
the surface, prediction tasks might seem to be easier. Responses simply require choosing between two presented options (e.g., former versus current hiding places), whereas explanation tasks require mounting a more self-initiated and extended causal argument. Thus prediction tasks have more the cognitive quality of recognition where explanation tasks demand production and recognition is often easier than production.

Yet an explanation advantage has been documented and replicated in several ToM studies using standard false belief prediction and explanation tasks with hearing preschoolers (e.g., Amsterlaw \& Wellman, 2006; Bartsch, Campbell \& Troseth, 2007; Bartsch \& Wellman, 1989; Rhodes \& Wellman, 2013). Importantly, these standard explanation tasks only require understanding of ToM-driven actions (e.g., Why did she go there for a bandaid?) in keeping with a standard false belief task's focus on predicting action ("Where will she go for a bandaid?"). As such they do not require more sophisticated meta-cognitive understanding of the causes for cognition (e.g., "Why does Ann think the bandaids are there?'). Wimmer \& Mayringer (1998) found no explanation advantage using meta-cognitive tests requiring children to explain an actor's reasons for thinking what she thought, as opposed to an actor's reasons for acting as she acted. Difficulty with reasoning about causes for beliefs is consistent with other research showing that tests of higher-order metacognitive "thinking-about-thinking" skills often lead to responses that are unclear and confused in young children, even including those who are already at ceiling on both prediction and explanation versions of standard false belief tests that carefully ask only about overt behavior (see Flavell, 2004; Miller, 2009 for reviews).

What could account for an explanation advantage on standard false belief tests? There are roughly two classes of proposal. First are interactional-familiarity accounts. Because TD preschoolers from age 2 on frequently engage spontaneously in explanatory conversation, asking and answering why-questions about human behavior many times a day (Callanan \& Oakes, 1992; Hickling \& Wellman, 2001), this interest and practice might promote surprising facility on ToM explanation tasks. Relatedly, educators (e.g., Chi et al., 1994) have demonstrated the power of students' explaining why an author or teacher has claimed something for the mathematical and scientific learning of children and adults, supporting a general claim that practice at explanation aids cognitive growth. Socio-cognitive conflict paradigms involving peers exchanging explanations for Piagetian conservation problems likewise show cognitive benefits from the act of explaining. Collaborators' gains on post-tests are typically greater than for control groups exposed to individual training (e.g., Perret-Clermont, 1980) and this is true even for dyads whose explanations during collaboration are consistently incorrect (Azmitia, 1996).

Other accounts propose in varied ways that explanation (including private "self-explanation" as well as the social exchange of explanations discussed above) is a fundamental human cognitive 
activity, a core part of the young child's attempts to make sense of the world. For example, from a theory-theory perspective, children are forming naïve theories of the world and a key function of theories is to frame and promote causal-explanatory understanding (e.g., Gopnik \& Wellman, 1994; 2012). A special cognitive status for explanatory understanding is part of many other perspectives within cognitive science, as reviewed by Lombrozo (2006).

More generally, such data and varied theoretical claims have helped fuel increased research into the nature, role and development of children's explanatory processes (e.g., Legare, 2012; Legare et al., 2009, 2010; Keil, 2006; Frazier, Gelman \& Wellman, 2009, 2016; Rhodes \& Wellman, 2012; Walker et al., 2014; Wellman, 2011). However, this burgeoning research has all been conducted with typically developing children, essentially those from advantaged backgrounds whose parents engage them in conversation, including frequent causal-explanatory exchanges. Better and broader understanding of children's putative explanatory prowess would be achieved by examining children who may not have "normative" interactional familiarity with explanatory conversation, whose daily upbringing encompasses vastly reduced requests and opportunities for explanation. For ToM specifically, comparisons of children with differing daily levels of exposure to conversationally discussing and explaining mental states would be especially informative.

Children born severely or profoundly deaf into hearing families are likely to be one such group. In the current research we focus on their explanatory competencies and, in particular, on whether an explanation advantage for ToM is present for them as for their hearing peers. In general, during early childhood, conversational access for many deaf children of hearing parents (DoH children) depends on their hearing family members' levels of signing skills. Yet, with some notable exceptions, these are often poor so that DoH children gain only limited early exposure to family conversations, especially causal talk surrounding mental states (Kritzer, 2008). "Most hearing parents who do sign are limited to relatively concrete conversation with little or no capacity for extended discussions in sign of social phenomena, or intangibles like thoughts and feelings" (Vaccari \& Marschark, 1997, p. 797). Yet, if at least one parent is a deaf native signer such mentalistic family conversation can proceed normally, though in sign rather than speech: that is, in a language that is fluently accessible to both conversational parties (Moeller \& Schick, 2006).

A review by Marschark et al. (2011) suggested that hearing adults more often take control of conversations when a child is deaf and, so as to avoid confusion, rarely mention their own doubts, mistakes, misunderstandings or faulty ideas. Similarly, for orally-communicating deaf children (including those with successful cochlear implants), easy access to spoken conversation is often not achieved for years after acquiring the implant (Schorr, Roth \& Fox, 2008) and often remains a significant challenge especially when conversing with other children or in group situations (e.g., Preisler, Tvingstedt \& Ahlström, 2005). Consequently even DoH children receiving their cochlear 
implants in toddlerhood are unlikely to have had as much access as hearing preschoolers to the informal causal-explanatory conversations about people that in hearing-only households are linked with early false belief success (e.g., Dunn, et al., 1991; Harris, 2006; Peterson \& Slaughter, 2003).

Thus studying these children's ToM explanations and ToM predictions presents important opportunities for further insight into how these two processes develop and interconnect with one another. Possibly, DoH children may be poor at explanation in general, and at ToM explanation in particular, given their likely reduced conversational exposure to formal (e.g., with parents) and informal (e.g., with peers and siblings) causal explanatory talk, especially about unobservable mental states. Thus, for them, the ToM explanation-prediction relation might be very different. In this vein, past studies have raised serious questions about deaf children's causal-explanatory thinking and willingness to use question-answer conversations to gain explanatory information even outside the ToM domain. Pioneering studies asked DoH children to produce explanations for rules of school comportment (Rachford \& Furth, 1986) or a novel game (Hoemann, 1972) and found substantially poorer performance than by younger hearing children. Further, Brice (1985) exposed 10-year-old DoH children to concrete demonstrations of puzzling phenomena and found they asked fewer whyquestions and were significantly more tolerant of cognitive ambiguity than hearing 6-year-olds. Unlike the latter they almost never offered their own explanations. Arnold, Palmer and Lloyd (1999) used referential communication tests and found that, compared to hearing peers, deaf 8-year-olds rarely or never requested necessary explanations or queried blatant ambiguities and omissions. More recently, Calderon and Greenberg (2003) likewise found that DoH children often misunderstood or ignored why-questions in conversation, thus concluding: "The impact of limited explanations and restricted experiences denies to many deaf children their rightful opportunity to learn to understand others" (p. 179)

Such findings suggest DoH children are relatively unfamiliar with the conversational exchange of "why" questions and answers, at least about ToM concepts. This could mean, according to interactional-familiarity accounts, that DoH children would not display an explanation advantage. Perhaps they might find both types of ToM test equally difficult. Still more likely, the simple pointing responses required by false belief prediction tasks could make them easier than false belief explanation tasks that require generating extended spontaneous conversational responses to "why" questions. Yet there are also reasons to predict that an explanation advantage similar to hearing preschoolers' could arise for DoH children as well. As noted above, explanation may be especially fundamental to human reasoning. If so, this could be true for deaf and hearing children alike. Children ponder the causes of things in private reflection (explaining to oneself), not just socially through the conversation or more formal instruction. In contrast to the social exchange of wellformulated "why" questions and answers, self-explanations are often merely "implicit and skeletal" 
(Keil, 2006) and hence potentially less dependent on conversational (or social-interactional) familiarity. Thus, complimenting theory-theory's explanatory emphasis, Keil and Wilson (2000) summarized some of these arguments and data by saying that, "explanations seem to be a large and natural part of our cognitive lives" (p. 1).

Beyond these arguments and evidence, which to reiterate, have exclusively considered hearing children and adults, there is tantalizing data from one prior study as to deaf children's possibly accurate explanations for mental states. Peterson and Slaughter (2006) asked a group of late-signing DoH children (5 to 12 years) to tell stories (in sign) in response to socially-complex, wordless pictures. Like hearing preschoolers, many deaf children who failed standard false belief prediction tasks not only described the pictured protagonists using simple cognitive words (e.g., "think") but also offered causally coherent accounts of mental states in the form of "elaborations" (e.g., "Her brother is pretending that he is a ghost") or even "explanations" (e.g., "She is scared because she thinks the ghost is real"). Since these DoH children mostly failed false belief (FB) prediction tasks these findings support the hypothesis (albeit indirectly) that DoH children could also evidence an explanation advantage similar to hearing preschoolers.

\section{The Current Research}

In two studies we compare FB explanation with FB prediction in DoH children. Since we are the first to do so, our study is novel and exploratory. Past evidence is too sparse and indirect to permit forecasting of precise directional hypotheses. Instead, any of the three possible outcomes (explanation advantage, prediction advantage or no difference between the two) all appear plausible in advance of empirical evidence. Importantly whichever of the three possible outcomes emerges, it will not only be informative with regard to deaf children but will also have theoretical relevance for a broader understanding of how concepts about false beliefs and their causes develop in all children irrespective of hearing status.

In this regard, it is important for theories of ToM to discover how explanations and predictions about people interconnect over development in children generally, not merely hearing ones. Further, owing to their slower ToM development than for hearing children or deaf native signers (Harris, 2006), studies of DoH groups can arguably supply unique insight into the developmental course of ToM-- in this case predictive and explanatory ToM competence. Comparisons between deaf and hearing groups can suggest testable hypotheses about the triggers for developmental change (e.g., early conversational experiences at home and at school) and are relevant to broad theories of the nature and development of ToM (e.g., experientially-driven conceptual change versus modular brain maturation: Slaughter \& De Rosnay, 2017; Wellman, 2014).

\section{Study 1}


Study 1 aimed to use well-matched standard tasks measuring FB prediction and explanation to test whether DoH children's ToM reasoning is characterized by an explanation advantage or, alternatively, whether they find explanation comparatively difficult. Possibly it might be as difficult as prediction, or even more so. Relatedly, we compare DoH children's false-belief (FB) explanation and prediction skills with those of younger hearing preschoolers of matched (and imperfect) ToM understanding. Making such comparisons (between explanation and prediction and between hearing and DoH children) requires not only good tasks but also convincing ways to code children's explanatory answers. Hence we developed and used both a "standard" coding system (parallel to that used in prior research with typically-developing (TD) children) and a more stringently conservative coding system for explanations that required explicit mention of cognition and thus was designed to reveal a convincing depth of DoH (and hearing) children's explanatory competence.

\section{Method}

\section{Experimental Rationale}

We compared deaf elementary school children (DoH) with TD hearing preschoolers. Although ages are different, these groups are well matched for our focal questions. In order to see if $\mathrm{X}$ (explaining false-belief actions) precedes or is easier than Y (predicting false-belief actions) we need to test children in both deaf and hearing groups who have not yet reached ceiling on $\mathrm{X}$ or $\mathrm{Y}$. Children who always pass both sorts of tests, or always fail them both, provide little or no information for this comparison. This dictated our design. Past research shows that (a) hearing children have typically reached ceiling on false belief prediction by about age 5 (Wellman et al., 2001) and (b) that many DoH children aged 6 to 11 years, while rarely at ceiling, will have at least begun to develop some skill at false belief prediction (see Peterson, 2009, for a review).

\section{Participants}

Seventy-five Australian children aged 3 to 12 years participated, in two groups. Group 1 had $31 \mathrm{DoH}$ children (mean age: 9.34 years; range: 5.83 to 12.42; 18 boys) from specialist bilingual hearing-impairment units using Auslan (Australian Sign Language) and spoken English as instruction media. Having grown up in hearing homes that, like most, are "neither fluent nor proficient" in sign (Goldin-Meadow \& Mayberry, 2001, p. 224), these children were "late-signers" whose daily immersion in a natively-fluent signing community (of peers and teachers) had typically coincided with their entry into formal schooling between age 4 and 5 . Nevertheless, by the time we tested them, all Group 1 children had signing skills that were, according to teachers, at least "adequate for everyday communication". They had either severe $(71+\mathrm{dB})$ or profound $(91+\mathrm{dB})$ prelingual hearing losses and 17 (55\%) had a cochlear implant. Precise information on age at implantation was unavailable to us. However, school records confirmed that all had received the implant prior to school entry (i.e., before about age 4.5 years). All the DoH children in our sample 
were bilingual in sign and speech to the extent that they (a) used both modalities to some degree on a daily basis and (b) all preferred bilingual testing to either sign or speech alone, as noted below.

Group 2 had 44 TD hearing preschoolers (mean age: 4.13; range: 3.08-5.00; 25 boys). Gender balance did not differ between groups, Chi-square (1) $<1, \mathrm{~N}=75, p=.914$, but mean age did, $t$ (73) $=17.33, p<.001$, as a necessary consequence of our experimental design that, as noted above, required children who were unlikely to score at ceiling on at least one of the two sorts of tasks. No Group 2 child was bilingual, according to teachers.

All in both groups had written parental informed consent and English as their family's sole or primary language. While precluded by the terms of our institutional ethical approval from seeking details of parents' incomes or educational attainments, teachers reported no serious economic hardship in this sample. All schools were government-funded (rather than private fee-paying) and drew from neighborhoods of predominantly middle socioeconomic (SES) status, each scoring above the $50^{\text {th }}$ percentile (in the advantaged direction) on the Australian government's "socioeconomic indexes for areas" (SEIFA: Australian Bureau of Statistics, 2011), a composite reflecting the neighborhood's median levels of parental education, income, rentals (versus home ownership), unemployment and proportion of unskilled occupations.

\section{Tasks and Scoring}

False belief prediction (FBP): Three standard false belief prediction (FBP) tests were given. One was a misleading container task from Wellman and Liu (2004): After guessing the expected contents of a closed box (e.g., crayons or eggs), children were shown that it contained something unexpected (e.g., a toy car). A naïve boy doll then saw the closed box, followed by a test question "What does he think is in the box?" and a control "Did he see inside the box?" A pass required both correct. Two tasks were standard changed-location items from Baron-Cohen et al. (1985): A girl put her ball inside a covered basket and departed. A boy moved it to a box (Task 1) or the experimenter's pocket (Task 2). The girl returned and the test question "Where will she look for her ball?" was followed by two control questions, "Where is the ball now?" and "Where did the girl put the ball in the beginning?" All had to be correct to pass. Summed, the total false belief prediction (TFBP) score ranged from 0 to 3.

False belief explanation (FBE). In a separate session, children received three false belief explanation (FBE) tasks. All were modeled closely on tasks used successfully in prior research with hearing preschoolers (e.g., Amsterlaw \& Wellman, 2006; Bartsch, Campbell \& Troseth, 2007) and all were likewise similar to the prediction tests (described above) except for the nature of the test question. For the misleading container explanation task, after guessing the contents of a closed pictorially-labeled bandaid box, children saw it was empty whereas a plain blue box held bandaids. A naïve girl doll with a bleeding knee wanted a bandaid and marched purposefully towards the 
labeled bandaid box. Children were asked "Why is she looking there?" along with a control question, "Where are the bandaids really?" The two changed-location explanation items involved pictorial stories about protagonists who became distracted (by a book, TV or phone) after seeing two items at specific locations on a table. The protagonist thus missed a crucial transposition of the items' positions (which the child witnessed) and acted upon a false belief (e.g., drank from a flower vase rather than a glass). Children's spontaneous signed or spoken replies to the ensuing test question (e.g., "Why is she drinking the flowers?") were recorded in full. If any child (rare in this sample) said "Don't know" or nothing, there was one repeat (e.g., "She's drinking the flower water, why?") but no further prompts. Thus children's own spontaneous explanations were elicited without any modeling or corrective feedback from the experimenter.

Scoring of explanations. Table 1 shows a sampling of explanations taken from both groups' transcripts. We coded these using two different scoring schemes. First, we applied a more lenient, "broadly epistemic" (BE) accuracy criterion that has been used effectively in many past studies of hearing preschoolers. Then to gain a more cautiously conservative picture of children's explanatory capacities (especially the DoH children's) we recoded their explanations with a novel "strictly cognitive" (SC) scheme. Both schemes are explained and illustrated in Table 1. Although our SC scheme was more stringent than previous studies' through its requirement that cognition be mentioned explicitly, we reasoned that the most conservatively compelling evidence for ToM arises when explanations accurately infer and label protagonists' mental states of ignorance or false belief using specifically cognitive verbs ("think", "know” or synonyms: see Table 1). However, in order not to underestimate children or neglect other informative aspects of their reasoning, we separately applied the BE scoring of past research. Specifically, Amsterlaw and Wellman (2006) had included mistakes (unintentional action) along with cognition in their most sophisticated "Belief/Mistake" (p.154) category and Wimmer and Mayringer (1998) included "epistemic" references to perception. Thus, our lenient BE scoring allowed intention, perception and/or cognition terms to qualify for a pass, but not desire terms since Wimmer and Mayringer (1998) argued these (e.g., "she wants a bandaid") merely explain going somewhere but not going to the wrong location. Similarly, following Amsterlaw and Wellman (2006), we did not count "situational" justifications as correct (e.g., references to the current or past physical positions of objects) although Wimmer and Mayringer had done so. Simply remembering that an object has moved does not guarantee that the child understands what is in the protagonist's mind. Invalid reasons (e.g., "because she thinks flowers are yummy") were also incorrect even if they included cognitive verbs.

Using these criteria, children either passed (1) or failed (0) each FBE task with no extra credit given for using multiple correct terms. Total scores (summed over the three tasks) could range from 0 to 3 for BE and (separately) from 0 to 3 for SC. The first author coded all transcripts. Then, to 
establish inter-rater reliability, a second coder (blind to children's ages, hearing-status and the study's hypotheses) used just the rules and examples in Table 1 to independently code a randomlychosen 86 responses representing both groups. Agreement between coders was almost perfect, $98 \%$. The few disagreements were resolved by discussion.

Language ability test. To assess general language skill we used the 22-item syntax ("Sentence Structure") subscale of the CELF (Clinical Evaluation of Language Fundamentals, Edition 1 (CELF/P): Wiig, Secord \& Semmel, 1992). This test has been used effectively in prior ToM research with typically developing children (e.g., Ruffman, Slade, \& Crowe, 2002) and with deaf children in the same age range as the present sample (e.g., Paatsch \& Toe, 2013; Peterson, Wellman \& Slaughter, 2012). It assesses a broad range of developmentally-sequenced lexical, morphological, and syntactic concepts via picture-pointing responses and is uniquely suitable for validly assessing linguistic maturity among Auslan users (see Wellman \& Peterson, 2013). Because no Auslan norms were available, we used raw total scores (out of the full 22 items) as the language measure for both groups (these are also better for comparing groups differing in age). All DoH children had complete language data. Six hearing preschoolers had missing data owing to school absence or other scheduling difficulties.

\section{Testing Procedure}

Children were tested individually at school by a male experimenter assisted, for all deaf children, by a professionally-qualified sign-language interpreter who translated the main experimenter's speech into Auslan and the child's Auslan into spoken words that the experimenter recorded. Interpreters were professionally accredited at the top interpreter level (Level 3) of Auslan signing skill by the peak national accreditation body in Australia, National Accreditation Authority for Translators and Interpreters (NAATI, 2011) and were already familiar to the deaf children from prior school interactions. The interpreter sat beside the main experimenter (both facing the child), translating the experimenter's speech into Auslan and repeating the child's Auslan orally for the experimenter to record. This bilingual mode of task presentation, a familiar part of everyday school routines, was preferable to sign alone since--despite all being signers--many children in the sample also used some oral communication on a regular basis. Hearing preschoolers took the tasks individually in the oral mode only. Data collection for Study 1 took place between March 2009 and February 2014.

\section{Results}

Table 2 shows children's scores on key measures. There was no significant difference between the groups in language skill, $t(67)=0.96, p=.340$. That DoH children averaged roughly $75 \%$ items correct (a clear pass) helps confirm reports by teachers that these DoH children had "sound" general language skills. Both groups likewise performed equivalently (and poorly) on false- 
belief prediction (TFBP). Only $16 \%$ of deaf children and $25 \%$ of hearing preschoolers (who were chosen to be younger than the normative false-belief mastery age: Wellman et al., 2001) passed TFBP by getting at least 2 of the 3 prediction items correct, a group difference that was not statistically significant, Chi square (1) $<1, \mathrm{~N}=75, p=.356$. Thus, as planned, there was room in each group for an explanation advantage to manifest itself. Prior to computing statistical analyses, we checked score distributions for normality. Shapiro-Wilk tests showed that TFBP, SC and BE scores were not normally distributed. Non-parametric tests were therefore employed for all analyses. To compare groups we used Mann-Whitney U tests. Monte Carlo confidence intervals (CI) around the $p$ values are also reported. For total SC explanations both groups scored equivalently, Mann-Whitney $\mathrm{U}=536.50, z=1.67, p=.096$, CI 95\% [.091, .102]. However, 14 deaf children (45\%) gave an SC explanation on at least 2 of 3 problems compared with only $23 \%$ of the TD group, a significant difference: Chi square (1) $=4.21, \mathrm{~N}=75, p=.040$. Similarly, DoH children outperformed hearing preschoolers on total broadly epistemic (BE) explanations, Mann-Whitney $\mathrm{U}=453.50, z=2.57, p=$ .010, CI 95\% [.007, .011] and 23 deaf children (74\%) but only 21 TD preschoolers $(48 \%)$ gave a BE response to at least 2 of the 3 explanation problems, Chi square $(1)=5.25, \mathrm{~N}=75, p=.022$. At the same time, a large majority of deaf $(87 \%)$ and of hearing (64\%) children managed to explain at least one false belief scenario using a correct BE reason, and this was a cognitive (SC) reason for $58 \%$ of the deaf and $43 \%$ of the hearing children. Thus both groups displayed skill with ToM explanation.

Comparisons between school-aged deaf children and hearing preschoolers are, of course, only suggestive because, despite equivalent ToM prediction scores, the two groups differed in many age-related ways. Therefore we tested for any "explanation advantage" (explanation superior to prediction) by analyzing Groups 1 and 2 separately. First we compared total BE explanation scores with total prediction (TFBP) scores. For the DoH children the BE explanation total was significantly higher than TFBP total, Wilcoxon $z=4.21, p<.001$, CI 95\% $[<.001,<.001]$ and the same was true for hearing preschoolers, Wilcoxon $z=2.99, p=.003$, CI 95\% [.001, .002]. Thus both groups demonstrated an explanation advantage in false belief understanding using this traditional BE scoring of past research. Next we made the same comparisons using our stricter cognitive (SC) scoring. For deaf children, the difference favoring SC explanation over prediction was significant, Wilcoxon $z=$ $2.74, p=.006, \mathrm{CI} 95 \%[.004, .007]$. But for hearing preschoolers, SC scoring yielded only a nonsignificant difference, Wilcoxon $z<1, p=.738$. Spearman correlations revealed that language ability was significantly linked with all three ToM measures for deaf children, all $r h o s>$ or $=.51$, all $p \mathrm{~s}<$ or $=.003$. For them, TFBP was also significantly correlated with age $(p=.034)$. For the hearing preschoolers, SC and BE were significantly correlated with language ability: rho $=.39, p=.017$ and $r h o=.46, p=.004$, respectively, but TFBP was not $(p=.253)$.

\section{Discussion}


Overall, a clear explanation advantage was demonstrated for signing deaf children aged 5 to 12 years, including when using a narrowly conservative scoring scheme that demanded explicit causal mention of cognition. Hearing preschoolers replicated past studies (e.g., Amsterlaw \& Wellman, 2006) in showing a clear explanation advantage when using traditional (BE) scoring that, like earlier studies', credited accurate intention- and perception-based explanations together with cognitive ones. But the advantage was not statistically significant using the stricter SC scoring. These results reinforce the view that the process of explaining is fundamental to early cognitive development (Keil, 2006), especially in the naïve psychological domain (Wellman, 2011). More specifically, they not only continue to confirm that hearing preschoolers are better at explaining the consequences of others' false beliefs than at predicting them, but also, for the first time, highlight how relatively proficient DoH children are at using ToM concepts to explain human behavior. For both deaf and hearing children alike, generating valid explanations for false-belief-driven behavior was significantly easier than making simple behavioral predictions about it and these school-age deaf children stood out also for often including cognitive verbs like "think" in their explanations.

Although differing baselines of chance success complicate precise comparisons between ToM explanations and predictions, we addressed this issue in two ways. First, we directly compared scores on closely-matched explanation and prediction tasks, regardless of baseline possibilities for spurious chance success. Ignoring chance baselines arguably works against finding better (or even equal) performance on ToM explanation because children could (and did) provide many possible kinds of explanations for the events presented in the stories, whereas the binary choice offered by a standard prediction task (e.g., predicting search of the basket versus the box) assures $50 \%$ odds of chance accuracy. This partly explains why the notion of an explanation advantage can initially seem counter-intuitive. Second, beyond the types of coding used in prior research, we assessed children's explanations via our more stringent cognition-only scoring scheme. Notably, DoH children's explanations outstripped their predictions even using this stringently conservative scoring.

It is worth considering whether (a) our prediction tasks might somehow have been spuriously difficult or (b) our explanation tasks might not have required genuine ToM understanding. Both possibilities seem unlikely. Our explanation tasks were taken from past studies of hearing children and were carefully modeled on standard changed-location and misleading-container prediction tests. Stories and overall procedures for both types of task were essentially the same apart from the test question (e.g., "Why does she look here?" versus "Where will she look?"). Furthermore, when children supply SC explanations like "Because she thinks the bandaids are in the box with the bandaids picture" it is hard to argue that they fail to understand false belief.

By the same token, our prediction tasks were exactly those used in prior research with deaf and hearing children (see Peterson, 2009; Wellman et al., 2001, for reviews) and these deaf children 
scored similarly to their counterparts in past studies (e.g., ours were $23 \%$ correct as against $17 \%$ for Italian DoH children in Meristo et al. (2007) and 32\% (at mean age 7) for Schick et al.'s (2007) U.S. sample). Thus it is hard to argue that our ToM prediction measures were somehow unusually or spuriously difficult compared to past research.

In this way, our deaf sample's poor FB prediction performance was no surprise. What was notable was how comparatively well these same children did on FB explanation. This is a novel and important finding. Of course it is also important not to overstate DoH children's competence at ToM explanation, or relatedly at ToM understanding. Even using the more lenient BE scoring of past research only $52 \%$ scored perfectly. More focally, even when deaf children gave sensible FB explanations, these did not translate into equally correct FB predictions. Though averaging five years older, the DoH children performed slightly worse than the TD preschoolers (mean TFBP $=.68$ versus .80) on the latter, although not significantly so. Conversely, even our youngest DoH children (aged 5 and 6 years) showed some explanatory competence (e.g., 67\% of those aged 7.00 years and under gave at least one correct BE explanation). Nevertheless, further investigation of DoH children's explanatory competence in future research is clearly desirable, including testing younger DoH children (provided they have sufficient language to comprehend the tasks).

As noted earlier, the difference in chronological age between our deaf and hearing groups was inevitable, given our research design and questions (i.e., to avoid uniform ceiling or floor effects in either group). Conceivably this age difference may have contributed to the deaf-hearing difference in frequency of SC explanations in some unknown way. This warrants exploration in future research. Meanwhile, however, it is important to note that our other (BE) scoring scheme is the one used by all past research on this topic and that using this standard scoring deaf and hearing children did not differ. Both groups displayed a clearcut, statistically significant FB explanation advantage using BE scoring. Furthermore the advantage was of equivalent magnitude in both groups despite their age difference. SC scores have the methodological strength of being cautiously conservative, but they are unique to our study. The evidence of the deaf children's explanation advantage with this additional more stringent measure is important, but further research using SC scores with other deaf and hearing groups is obviously needed before definitive conclusions or wider implications can validly be drawn.

\section{Study 2}

A crucial theoretical question concerning explanation's advantages over prediction for deaf and hearing children alike concerns whether and how explanation assists further learning. Conceptually, being required to explain a now-apparent but unexpected fact or occurrence often makes the limited nature of one's understanding blatantly obvious (Keil, 2006). Empirically, mounting evidence from studies of TD hearing children in numerous paradigms suggests that 
generating causal explanations may supply a mechanism for causal learning (Keil, 2006; Lombrozo, 2006). When asked repeatedly to explain events, TD children's learning often exceeds that of nonintervention control groups. The quality of subsequent explanations, predictions, and/or information retention have all been seen to improve over time for both preschoolers (Amsterlaw \& Wellman 2006; Frazier, Gelman \& Wellman, 2016) and school-age children (Chi, DeLeeuw, Chiu, \& LaVancher, 1994). These effects do not require any feedback as to the adequacy of one's explanation; explanatory effort is sufficient.

But of course, things could be different for deaf children. If so (or if not) this would be theoretically interesting. Returning to the theoretical alternatives outlined in our introduction, but now focusing specifically on learning, it is interesting to speculate on possible mechanisms that could contribute, within the ToM domain, both to children's learning how to explain, and to their learning from explaining. Perhaps explanatory attempts operate at a fundamental level to facilitate conceptual development. They might, as Keil argued, work by emphasizing one's unexpected ignorance. Equally, or alternatively, because explanations for misguided actions are initially more sophisticated than corresponding predictions (as demonstrated for both deaf and hearing children in Study 1) the act of explaining may well motivate children to muster their most advanced ToM reasoning. This could conceivably provide a helpful platform for further insightful learning, ultimately assisting prediction as well. Indeed, for hearing children, being asked for ToM explanations in extended microgenetic sessions has been shown to boost subsequent performance on false belief prediction tests (Amsterlaw \& Wellman, 2006; Rhodes \& Wellman, 2013).

An initial study, such as ours, cannot directly or deeply adjudicate between such theoretical alternatives. But it could take a needed step by establishing whether or not DoH children improve after being required to engage in explanatory effort in the context of ToM problems. Because deaf children are arguably exposed less often to explanatory conversational exchanges in general (see e.g., Wood \& Wood, 1997 and Marschark at al., 2011 as outlined in the introduction) then if DoH children's conceptual gains from being asked to explain people's puzzling actions turn out to resemble hearing children's, this could prove suggestive. So too would the alternative possibility namely that extended practice in generating explanations fails to benefit ToM understanding for DoH children, contrary to some past evidence for hearing children. If such practice leads to subsequent gains for the deaf, this could generate further hypotheses. For example, the impact of explanation may operate via more fundamental cognitive mechanisms such as a universal human drive for ever greater understanding (Keil, 2006). To examine this, we designed an intervention study exposing DoH children intensively to the challenge of explaining acts of paradoxical ToM-driven behavior.

One prior study in particular sets the stage for our research. Using a microgenetic training approach, Amsterlaw and Wellman (2006) gave hearing children $(\mathrm{N}=12)$ practice at generating 
explanations for a protagonist's false-belief-based behavior over multiple tasks spread over six weeks. Half the problems involved unseen displacements and half, misleading containers. On every trial a full false belief prediction test was initially given in standard format with a prediction test question (Where will Sally look for her ball?). Then the test story continued with the protagonist acting on the basis of a false belief, providing implicit feedback about whether the child's prediction was correct. A FB explanation test question followed (e.g., "Why is she looking in the drawer?"). If no explanation was spontaneously forthcoming, the protagonist's cognition was queried (e.g., "What does Marcia think?"). The 12 children in the focal microgenetic training group, who explained 12 or 24 problems in their multiple sessions over 6 weeks, evidenced significant improvements on standard false belief (FB) prediction tests at posttest relative not only to pretest and but also to two control groups, one with microgenetic sessions of false belief prediction and another with no intervention. As well as improving on FB prediction, the focal training group displayed generalization to another type of ToM task (knowledge access), although not to an appearance-reality test assessing awareness that an object can look like one thing (e.g., an apple) but really be something else (e.g., a candle). These findings (also see Rhodes \& Wellman, 2013) provide evidence that giving hearing preschoolers extended practice with explaining and predicting can result in higher scores on standard FB prediction tests post-tests.

We followed a modified version of this template in Study 2 to explore FB explanation training in a sample of 25 school-aged DoH children. Our main change was to omit the FB prediction training that each of these past studies had included along with FB explanation practice on every training trial. Thus, as well as focusing on deaf children, our training procedure was novel in testing whether FB explanation practice can be given alone, versus whether it must be combined with FB prediction practice, in order to result in post-test gains. This in itself was an important methodological refinement that could help to narrow down the focal conditions responsible for past effects of FB explanation training. We also had a non-ToM control group. It was an "active nonintervention" or "placebo" control (Boot, Simons, Stothart \& Stutts, 2013) that, similar to the training group, engaged in interesting individualized activities with an experimenter and an Auslan interpreter, albeit with no ToM content. This type of control has the advantage over a pure nonintervention control (where nothing except time intervenes between pretests and post-tests) of ruling out the hypothesis that merely growing older and/or participating in interesting activities could fully explain any post-test gains made by the focal training group.

We predicted that children in our focal ToM-Training group (who were exposed, like Rhodes and Wellman's (2012) and Amsterlaw and Wellman's (2006) hearing children to 12 micro-genetic sessions with a story protagonist acting out FB-driven behaviors followed by requests to explain her actions) would display higher post-test FB prediction scores than at pretest. Moreover, we predicted 
they would outperform the appropriately matched children in the non-ToM control group who, we predicted, would make little or no ToM progress.

\section{Method}

\section{Experimental Design}

The procedure involved four phases: a pretest, an intervention, an immediate posttest and a delayed posttest. At pretest children received a battery of four standard false belief prediction tests. Eligible children were then selected as those who consistently failed these at pretest. We defined this stringently via the requirement that the child must have failed at least $75 \%$ ( 3 of 4 ) of pretest falsebelief-prediction items. This ensured that all children (both intervention and controls) had room to improve prior to the intervention.

For the intervention phase, the ToM-training group was given explanation practice with 12 FB explanation scenarios (modeled closely on Amsterlaw and Wellman's 2006 study: see Table 3), presented in 3 blocks of 4 problems per session. Each session was separated from the next by 2 to 4 days. Thus training extended over a 3-week period, followed by the immediate post-test and, roughly 12 weeks later, a delayed post-test to address whether ToM gains, if any, persisted over time.

The control group took the same pre- and post-tests as the ToM-training group and the gap between these was the same (see details below). Rather than ToM explanation, however, they engaged in a 45-minute artistic (visual representation) problem-solving activity that had no ToM content. It was closely modeled on the procedures of Wellman and Peterson (2013).

\section{Participants}

The full sample of 25 DoH children in Study 2 (17 boys) had a mean age of 8.96 years (range: 6.25 to 13.08). None had taken part in Study 1. Just as in Study 1, children were preselected as having prelingual hearing losses that were either severe ( 85 to $90 \mathrm{~dB}$ ) or profound $(91 \mathrm{~dB}$ or greater) and were recruited from two specialist units for hearing impairment located within government-funded primary schools where a bilingual (sign-plus-speech) mode of communication was employed. All the children had hearing parents, and, despite access to early intervention and efforts by some parents to learn some signs, their teachers reported that no child in this sample had any family member at home who used any form of signing as fluently as a native speaker. Further eligibility requirements included: (a) freedom from disabilities apart from hearing loss, (b) English as parents' sole or primary language, (c) written parental informed consent, and (d) at least one full year's attendance at the bilingual school coupled with Auslan skills rated at least "adequate for everyday communication" by teachers.

We allocated children into two groups--11 to the focal ToM Training group and 14 to the non-ToM Control group--on a semi-random basis with the constraints that (a) the two participating schools were equally represented in training and control groups, and (b) younger and older children 
were distributed across groups as equally as possible. Subsequent statistical comparisons confirmed that these precautions were successful and that groups were well-matched in several respects: There were no group differences for (a) school attended, Chi-square (1) $<1.00, \mathrm{~N}=25, p=.622$, (b) mean age $(\mathrm{M}=9.75$ and 8.34 years respectively), $t(23)=1.96, p=.062$, (c) gender balance, Chi-square (1) $<1.00, \mathrm{~N}=25, p=.653$, (d) proportions with cochlear implant(s) (54\% and 29\%), Chi-square (1) $=1.73, \mathrm{~N}=25, p=.188$, or (e) mean language ability, $t(23)<1.00, p=.887$.

\section{General Procedures}

Each child in the ToM training group was individually tested on all tasks in a bilingual modality (sign + speech: see Study 1) in a quiet school area. For the control group's pretests and post-tests the same was true. But their "placebo" intervention involved not only periods of individual (bilingual) interaction (with the same experimenter and interpreter as for the training group), but also periods of working alongside 1 to 4 other children in a small group on an art activity. For all children, task presentation and interpretation procedures were exactly as in Study 1, with the interpreter translating experimenter's speech into Auslan for the child, and vice versa. All interpreters were fully professionally accredited Auslan interpreters (NAATI, 2013). Data collection for Study 2 took place between March 2014 and October 2014.

ToM pretests. Before their intervention began, all children in both groups were individually pretested on a battery of standard FB prediction tasks, two involving changed locations (both trials of Baron-Cohen et al.'s (1985) Sally-Ann task) and two involving misleading containers (a toy car in a crayon box and a candy box containing pencils). Procedures, questions and scoring matched Study 1 's, including the requirement for perfect accuracy on a task's control as well as test questions for a pass.

Language ability pretest. The Sentence Structure (Syntax) subscale of the Clinical Evaluation of Language Fundamentals (CELF-P) test (Wiig, Secord \& Semmel 1992) was presented and scored just as described for Study 1.

\section{Intervention Phase and Procedures}

ToM intervention. The ToM-explanation intervention was modeled closely on Amsterlaw and Wellman (2006) with one major modification. Rather than including any FB prediction questions or corrective feedback, our training omitted both of these. Each training task began with a protagonist acting on the basis of a false belief (see Table 3) followed by the FB explanation question ("Why...?). Our rationale for excluding Amsterlaw and Wellman's (2006) use of a prediction test question on each trial prior to the focal explanation test question was twofold. First, the language for asking FB prediction questions (e.g., "What does James think is in the lunchbox?") could cue children to use verbs like "think" in their explanations. Second, with Amsterlaw and Wellman's method, the implicit corrective feedback given to children who fail the FB prediction test 
questions during training could add to (or even substitute for) any benefit directly attributable to the act of explaining. Thus (as noted above) our training more conservatively tested possible benefits from FB explanation practice alone, without concomitant FB prediction practice. Half our training tasks (see Table 3 ) involved changed locations and half misleading containers. Within each half, dolls and props were used half the time and picture-book stories about real children for the other half. No differences were observed as a function of these variations in task format. Our sample, like Amsterlaw and Wellman's focal group, received a total of 12 false belief explanation problems. For us, these were presented individually in 3 separate sessions of 4 problems each. Sessions were spaced 3 to 7 days apart across a total span of roughly 3 weeks.

As Table 3 shows, the ToM-training group's scenarios closely resembled standard FB prediction tasks in all respects except the wording of the test question (e.g., "Why will she look" rather than "Where will she look"). Children's answers to test questions were recorded verbatim in full. If a control question (e.g., "Where are the bandaids really?") was answered incorrectly (rare in this sample), the story and questions were repeated once. No more than one repetition was ever necessary. Finally, if the child's explanation did not include a cognitive term, the supplementary question "What is he [she] thinking?" was asked, just as in Amsterlaw and Wellman (2006). The next task began immediately so that no corrective feedback or any other implicit or explicit instruction was ever given. Thus, strictly speaking, children were not "trained" either about FBs or about how best to explain them. Nor were they informed as to the accuracy of their own spontaneous explanations. Instead, they were merely given extended practice with "why" questions that encouraged them to consider the causal basis for protagonists' unexpected reality-discrepant behaviors, together with the subtle suggestion to consider the protagonist's mental state ("What does she think?") if they failed to spontaneously mention cognition in their explanation.

Control intervention. The control group's intervention occupied the same interval from preto post-tests as the ToM-training group's (means $=26.17$ and 25.45 days, respectively: $t<1, p=$ .711). As noted earlier, it consisted of a visual-representation exercise offering general practice in following task instructions, deploying attention between teacher and interpreter and dealing with representational materials, albeit in a manner that was visual and pictorial rather than mentalistic. Briefly, a visual stimulus (e.g., a photo of elephants, a vase of real flowers, etc.) was shown and, as in ToM training, a short introductory narrative framed the exercise (e.g., "Look at this photo: What are these? Yes, elephants. Look: there is a big one, a small one and [point] what size is this? Yes, middle-sized. Now here's your paper. You draw three elephants. Do them so they fill the whole page. Use lots of color. Try to do yours just like the picture. Make one big, one small and one middle-sized"). After children began to work, the experimenter and interpreter visited each child individually in turn. Using the same bilingual mode as for ToM testing, individualized comments 
included specific suggestions and general encouragement while taking care never to mention thoughts, intentions, beliefs or other mental states.

\section{Post-Test Procedures and Scoring}

Immediate post-tests. The immediate posttest had four standard FB prediction tests (two involving changed-locations and two involving misleading containers). These mirrored those used at pretest with different scenarios, pictures and props. In addition there were two appearance-reality FB prediction tests (Lohmann \& Tomasello, 2003). There was also a knowledge-access (KA) task at immediate and delayed post-test (see Peterson, Wellman \& Liu's (2005) Appendix for exact wording) to assess generalization to a novel (untrained) ToM concept other than FB. All 11 children in the ToM-training group took the immediate posttest but two in the control group missed it owing to protracted school absence. (Both were available for the delayed posttest and so were retained for all analyses not involving the immediate posttest).

Delayed post-test. For the delayed posttest (assessing retention over 3 months) we used new dolls and materials for the four core false belief prediction items (i.e., two new Sally-Ann-type tasks and two misleading container tasks) plus knowledge-access.

Total post-test scores. The core measure of false-belief-prediction skill for each of the testing phases (pretest, immediate posttest and delayed posttest) was a four-item total false belief prediction (TFBP4) composite summing scores on the two misleading container and the two changed-location items. At immediate post-test there was a six-item TFBP6 score summing TFBP4 with the two appearance-reality FB tasks requiring prediction of a naïve other's belief about the true identity of a deceptive item. The single knowledge access (KA) generalization item was scored pass (1) or fail (0).

\section{Results and Discussion}

Results are considered first in terms of changes in children's performance on standard FB prediction tests as a result of our focal ToM training (involving explanation but not prediction). Next we examine possible differences between children in the training group versus the control group on the immediate and delayed posttests. Finally we explore the specific explanations generated by children in the training group during their training sessions and whether these relate to increases on their post-test FB prediction scores relative to pretest.

\section{Changes in False Belief Prediction Skills from Pretest to Post-tests.}

Figure 1 shows the primary measure, mean total false belief prediction (TFBP4) scores at pretest, immediate post-test and delayed post-test. As the figure illustrates, children in the ToMtraining group gained significantly from the pretest to the immediate posttest in scores on standard misleading container and changed location false belief prediction tasks. As in Study 1, nonparametric Wilcoxon tests were used (owing to the non-normal distribution of TFBP4 scores) and we also report 
Monte Carlo confidence intervals around the $p$ values for significant effects. For the ToM-training group, there was a significant gain from the pretest to the immediate posttest in TFBP4 scores (see Figure 1 and Table 4), Wilcoxon $z=2.63, p=.007$, CI 95\% [.006, .009]. Furthermore, at delayed post-test, their TFBP4 scores were also significantly higher than at pretest, Wilcoxon $z=2.72, p=$ .006, CI 95\% [.004, .007] indicating maintenance of their significant gains 12 weeks later. By contrast, the non-ToM control group did not improve significantly on TFBP4 from pretest to either the immediate post-test, Wilcoxon $z=.45, p=.655$, or the delayed post-test, Wilcoxon $z=1.55, p=$ .121 .

\section{Post-test Comparisons between Training and Control Groups}

As Figure 1 illustrates, both groups scored equally on TFBP4 at pretest $(p=.572)$ but there were significant group differences on TFBP at the immediate post-test, Mann-Whitney $\mathrm{U}=22.50, z$ $=2.78, p=.004$, CI 95\% [.003, .005] and at the delayed post-test, Mann-Whitney $\mathrm{U}=33.50, z=$ $2.49, p=.013$, CI 95\% [.011, .015]. The ToM-training group significantly outperformed the control group at both times. On the single KA item testing for generalization to a ToM concept not used in training there were no statistically significant group differences at immediate post-test or delayed post-test (see Table 4 for means). However, there was a trend for those in the ToM-training group to outperform the control group at immediate post-test, Chi square $(1)=3.49, \mathrm{~N}=23, p=.062$.

\section{Explanations during training}

Notably, each child in the ToM-training group gave a coherent explanation for each of the 12 training problems (there were no "don't knows"). This indicated consistent interest and involvement with the task and highlighted Study 1's findings that a drive to explain paradoxical human action is clearly evident in DoH children. Their consistent responsiveness indicated, furthermore, that all children could account plausibly (to their own satisfaction if not to ours) for the mistaken behavior in each of the training stories. We used the same strict scoring scheme as in Study 1 to tally both BE (broadly epistemic) and SC (strictly cognitive) explanations. As in Study 1, SC explanations had to explicitly mention a cognitive verb (e.g., "think") in an appropriate (causally antecedent) context. Similarly, BE explanations had to appropriately invoke an epistemic state of perception, intention or cognition (Tables 1 and 3 give examples). Desire (e.g., "want") explanations, while common, were not credited for reasons detailed in Study 1. The same was true of situational explanations (devoid of mental state terms) and non-causal mentions of an appropriate verb. Explanation performance of the training group during training partially replicated Study 1. On the first 4 training trials correct BE explanations (normally distributed) were significantly more frequent than correct FB predictions on the first 4 pretest items, $t(10)=2.80, p=.019$. Moreover, 9 of the 11 ToM training-group children $(82 \%)$ used a correct BE explanation at least once during training, constituting $27 \%$ of total training 
explanations. Correct SC explanations were used by 6 of the 11 children (55\%) at least once during training.

There were also wide individual differences within the ToM-training group in children's frequencies of using BE and SC explanations. To see if these were connected with training's effectiveness, we computed correlations with post-test FB prediction scores. (We used nonparametric Spearman correlations for these analyses owing to the non-normality of TFBP score distributions). Children's total SC explanations during training correlated significantly with their TFBP prediction scores on both the immediate post-test, $r h o=.62, p=.041$ and the delayed post-test, rho $=.77, p=$ .006. But there was no correlation of training SC scores with pretest TFBP, implicating explanation performance during the training phase, rather than pre-existing false-belief prediction skill, in the post-test associations. Correlations for BE explanations during training trended in a similar direction, but were non-significant (all $r h o s<$ or $=.55$, all $p \mathrm{~s}>$ or $=.079$ ) possibly due to the small sample size and the fact that all but two children gave at least one BE explanation during training, resulting in little individual variability.

\section{Study 2 Conclusions}

After repeated practice devising their own explanations for story protagonists' realitydiscrepant actions during training, the children in our ToM-training group showed significant gains in false belief prediction relative to pretest and these were still apparent 3 months later. By contrast, the control group made little or no ToM progress, ruling out general factors like passage of time or opportunities for special activities as the factors accounting for progress by the focal group. Our study is an advance in this regard over some prior ToM-training studies of hearing preschoolers that have often overlooked the need for any sort of active non-ToM control or indeed (sometimes) for any control condition at all. Without this, simply observing progress in the intervention group does not validly permit the conclusion that the intervention itself made any difference.

Arguably, our focus on DoH children for this demonstration is advantageous. It shows that experiences with ToM explanation can result in post-test gains even for a group whose ToM development would, without intervention, proceed slowly over a very prolonged time period. This unusually protracted timetable for spontaneous ToM mastery by DoH children is instructive. In contrast to TD children, who ordinarily master false belief so rapidly that spontaneous gains might arise without intervention between pretest and delayed post-test, this was much less likely for our DoH children (Peterson \& Wellman, in press). Also, unlike some past studies of hearing preschoolers (e.g., Amsterlaw \& Wellman, 2006) our focal training intervention did not include either practice with FB prediction or feedback on explanation or prediction accuracy. Nor did it include any exposure to the well-crafted model explanations created by adults that have been used in some past ToM-training studies of hearing children (e.g., Lecce, Bianco, Demicheli \& Cavallini, 
2014). Instead, in our study, DoH children were simply faced with the challenge of explaining story protagonists' unexpected reality-discrepant actions. All in our sample rose to the challenge and managed to devise their own accounts of why the story protagonists were behaving so oddly, even if these were not always adequate by adult standards. That is, after being asked to explain, and finding a way to do so, even children whose explanations did not explicitly refer to epistemic mental states displayed improvement on FB prediction post-tests. Our study has the limitation, however, of only having a single control group. Thus while supportive of the inference that something about the ToM intervention we used was more beneficial than a matched control intervention devoid of ToM content, we cannot identify with certainty what this "something" was.

Our preferred hypothesis is that the key ingredient is DoH children's greatly enhanced practice with ToM explanation during our intervention. Yet because of the limitations of our control group, it is admittedly unclear whether improvement resulted from engaging in explanation or merely from being exposed to ToM materials and questions. Training research with typically developing children has shown that, for them, mere exposure to ToM materials is insufficient to produce training improvement (e.g., Amsterlaw \& Wellman, 2006; Lohmann \& Tomasello, 2003) suggesting the same could be true for deaf children, especially given their pre-existing ToM delays. However this is an empirical question that needs to be examined in future research. In particular, future research could examine this issue directly by including an additional control group that would be exposed to the same ToM stimulus materials but without any requests to generate explanations.

In broad terms, our findings have the general theoretical implications outlined at the start and supported by findings of Study 1. Because our participants were DoH children who arguably experience a paucity of explanation requests (especially ToM-relevant ones) in their homes and classrooms, and are known to be reluctant to ask why, our data argue against the hypothesis that training such as ours can only assist children with long and varied practice in seeking and receiving mental-state explanations during social interaction and conversation in everyday life from toddlerhood (Keil, 2006) onwards. Instead our findings appear more consistent with the view that general cognitive processes recruited by explanation attempts may underpin the gains observed. Of course, further evaluation and support for such hypotheses depends on additional research, including future studies using multiple control groups.

\section{General Discussion}

Results of both studies highlight the importance of FB explanation in relation to two broad interpretations outlined in our introduction. Study 1's demonstration of an FB explanation advantage over FB prediction for DoH children, just as for the hearing, is in line with suggestions that the drive to understand and explain represents a fundamental outcome of, and contributor to, cognitive development and learning across many different cultural, individual and family situations (e.g., Keil, 
2006; Lombrozo, 2006; Wellman, 2011). As Keil (2006) noted, "Explanations in their own right can be immensely rewarding things and may be sought out as such, even by the youngest of children" (p. 234). Perhaps this helps to explain superiority of deaf and hearing children's ToM explanations over their ToM predictions in Study 1, as well as the post-test ToM gains the DoH children displayed after completing our training intervention in Study 2.

Of course, with only cross-sectional and training data to go on, current research (our own and that of other past studies) cannot not yet demonstrate that explanation is fundamental for children in the sense of being a naturally-occurring chronological precursor to prediction. Future longitudinal studies would be useful to examine the spontaneous emergence of ToM-relevant explanations and predictions. Longitudinal research with DoH children would be an especially welcome addition to such a project. Given DoH children's presumed reduced exposure to the everyday conversational exchange of "why" questions and explanations, our data suggest that the search to explain perplexing human behavior may be cognitively fundamental for all children in the sense of a readily available and important platform for learning. Explanations have the potential to scaffold ToM growth and, as we noted earlier, this possibility is supported by Study 2's findings. Arguably the act of explaining coupled with an explanation advantage evokes some of a child's most advanced cognitions (in line with results of Study 1). Relatedly, Legare, Wellman and Gelman (2009) demonstrated an explanation advantage (over prediction) for preschoolers' naïve biological reasoning about contamination and infection. This too suggests that explanatory reasoning is arguably a cognitive fundamental. That deaf children in particular, along with hearing children, become so easily engaged with the task of explanation accords with Keil's (2006) view that, "all of us throughout the world share the same drive for explanation" (p. 44).

If so, what sort of mechanisms might account not just for children's interest in explanations but their relative competence with explanation relative to prediction? Wellman and Liu (e.g. 2007) have argued that much everyday explanation may be cognitively easier than prediction. Prediction often entails open-ended uncertainty among a great many potential outcomes. Even in cut-and-dried location-change false-belief tasks, the protagonist might search for his desired candy in location A, or B, or perhaps nowhere (e.g., if he is no longer hungry or assumes someone else has already eaten it) or even in both places at once (because he thinks equally desirable identical candies are actually in both locations), and so on. But often explaining merely requires post-diction of known outcomes that can be accounted for after the fact. The protagonist is in fact searching for his candy in location $\mathrm{X}$. That is a given. So all the child has to do is come up with a reason why. Hence explanation very often (though not always) requires post-diction. Not just in children's thinking but also in scientific theorizing, predicting future outcomes in situations of uncertainty is often deemed to be a particularly challenging undertaking whereas post-hoc post-diction is often easier. 
Explanation's advantage for FB learning could additionally involve the mechanism described earlier: Explanations evoke some of a child's most advanced cognitions and this in turn could scaffold ToM growth by making such reasoning more practiced and consciously available. Possibly, many factors are at play in past demonstrations of any explanation advantage for ToM tasks. For one thing, adult-child conversations could drive early propensities for explanatory sense-making. When children ask and answer "why" questions their everyday cognition is often directed at understanding recent events, especially those involving human acts and motives. Also, the ease of post-diction might contribute to early, formative explanatory successes. Thus satisfaction at having resolved an explanatory puzzle could motivate further efforts and successes and these could ultimately benefit prediction as well.

Besides their theoretical value, data from both studies suggest there could be practical value to be gained from eliciting and encouraging explanations from DoH children. In particular, our findings suggest this could benefit ToM development specifically, although in theory, this could also apply more broadly to other domains of knowledge. Of course, with only 11 DoH children in Study 2's ToM-training group, and only a single control group, our results are clearly tentative and require replication and extension before such practical applications are attempted. Further research both in the ToM domain and more broadly could address this. Meanwhile our data demonstrate the promising potential of an intervention as simple as being asked "Why?" as a possible stimulus to cognitive growth.

Indeed, could greater use of "why" questions in classrooms benefit deaf children's education? Our Study 2 data do not directly address educational benefits of explanatory efforts for DoH children. Yet they do enhance the plausibility of testable hypotheses such as that the successful sharing of "why" questions and explanations through conversation (especially with fluently signing peers or teachers) could be particularly helpful for these children. This is further suggested indirectly by evidence of DoH children's superior performance on cognitive tasks (Piagetian conservation and justice reasoning) after having explained their views to signing deaf peers in socio-cognitive conflict paradigms (e.g., Peterson \& Peterson, 1990). Children who debated with a signing deaf partner and attempted to explain their conflicting views made significant gains on individual conservation posttests irrespective of whether or not the dyad had achieved a correct solution while interacting. Thus, hypothetically, training interventions incorporating explanation could conceivably prove helpful for boosting deaf children's understanding not just of ToM but also in many other cognitive domains.

Other aspects of our findings also warrant continued research. For example, it would be useful to investigate explanatory ToM reasoning in still younger DoH children. Admittedly this would be difficult because their delayed language competence means younger DoH children would often lack the linguistic resources necessary for understanding and generating the kinds of extended 
verbal explanations that our sample produced. Unlike FB prediction, FB explanation questions cannot adequately be answered via simple monosyllables or finger-pointing. However, it remains possible that merely being asked "why" questions can engage young (and deaf) children's drive for explanation even in the absence of the overt production of a satisfactory explanation (e.g., Azmitia, 1996; Peterson \& Peterson, 1990) or perhaps any explanation at all. Relatedly, tasks where children can reveal their explanatory curiosity via exploratory manipulation of objects (e.g. Legare, Zhu \& Wellman, 2013; Walker et al., 2014) could be feasible for this group.

Whether the explanation advantage is especially pronounced for deaf and/or hearing children when explaining intentional human actions is intriguing. Explanations appear very early and broadly for typically developing children (e.g., Keil, 2006) and human behavior has been found to be a particularly compelling magnet for young children's interest and explanatory prowess (e.g., Callanan \& Oates, 1992; Hickling \& Wellman, 2001). Deaf children too might be more motivated to try to explain socially relevant acts than purely academic material. However, without direct evidence from DoH children, this is only one of several possibilities that further research could helpfully address. Naturalistic studies of DoH children's spontaneous conversations with hearing-speaking family members and signing peers could also prove revealing. It would be interesting to actually know how often "why" questions and answers, especially about people's mental states, are spontaneously exchanged and with whom. Further, even if causal-explanatory discourse turns out to be infrequent, DoH children might engage in it sometimes and in revealing ways. A possible first step would be to have caregivers compile diary records of deaf children's spontaneous "why” questions and answers, as in Callanan and Oakes' (1992) study of hearing children.

Meanwhile, the current studies make several important contributions. First, they contribute to burgeoning literature suggesting that the simple act of explaining can promote cognitive development in children generally. Lombrozo's (2006) proposal that "Explaining novel information to oneself can facilitate learning... and foster generalization” (p. 471) aligns with our Study 2 finding that our focal explanation intervention resulted in superior post-test performance over pretest. This arose not only on FB prediction tasks that used scenarios similar to training but also on completely new types of post-test FB prediction problems. Furthermore, the specific explanations that the children in the training group generated, while satisfying to themselves, did not always meet adult standards for a convincing ToM-based argument.

The exact mechanisms responsible are uncertain and clearly require further study. Nonetheless, our findings reinforce the value of pursuing explanation research as an avenue towards greater scientific understanding of the development of ToM and cognition generally. They also initiate new methods and new populations for the pursuit of these research directions. Third, our findings enhance the understanding of the processes of ToM development, both typically and amid 
delay. Fourth, they highlight the need for further investigation of a novel and straightforward intervention (asking why) that merits applied evaluation in practical settings as a possible means to assist not only DoH children's overcoming of ToM delays but also the formal and informal education of children generally.

\section{References}

Amsterlaw, J., \& Wellman, H. M. (2006). Theories of mind in transition: A microgenetic study of the development of false belief understanding. Journal of Cognition \& Development, 7, 139172. doi: $10.1207 / \mathrm{s} 15327647 \mathrm{jcd} 0702 \_1$

Arnold, P., Palmer, C., \& Lloyd, J. (1999). Hearing-impaired children's listening skills in a referential communication task: An exploratory study. Deafness \& Education International, 1, 47-55. doi: 10.1179/146431599790561451

Astington, J. W. (2001). The future of theory-of-mind research: Understanding motivational states, the role of language, and real-world consequences. Commentary on 'Meta-analysis of theoryof-mind development: The truth about false belief'. Child Development, 72, 685-687. doi:10.1111/1467-8624.00305

Australian Bureau of Statistics (2011). Census of Population and Housing Socioeconomic Indexes for Areas (SEIFA) 2033.0.55.001. Canberra: ABS (www.abs.gov.au).

Azmitia, M. (1996). Peer interactive minds. In P. Baltes and U. Staudinger (Eds.) Interactive minds (pp. 133-162). Cambridge (UK) Cambridge University Press.

Baron-Cohen, S., Leslie, A., \& Frith, U. (1985). Does the autistic child have a "theory of mind?" Cognition, 21, 37-46. doi:10.1016/0010-277(85)900228

Bartsch, K., Campbell, M. D., \& Troseth, G. L. (2007). Why else does Jenny run? Young children's extended psychological explanations. Journal of Cognition \& Development, 8, 33-61. doi:10.1207/s15327647jcd0801_2

Bartsch, K., \& London, K. (2000). Children's use of mental state information in selecting persuasive arguments. Developmental Psychology, 36, 352-365. doi:10.1037/0012-1649.36.3.352

Bartsch, K., \& Wellman, H. (1989). Young children's attribution of action to beliefs and desires. Child Development, 60, 946-964. doi:10.2307/1131035

Boot, W., Simons, D., Stothart, C. \& Stutts, C. (2013). The pervasive problem of placebos in psychology. Perspectives in Psychological Science, 7, 582-584. doi: $10.1177 / 1745691613491271$

Brice, P. (1985). A comparison of levels of tolerance for ambiguity in deaf and hearing children. American Annals of the Deaf, July, pp. 226-230. 
Calderon, R. \& Greenberg, M. (2003). Social and emotional development of deaf children. In M. Marschark \& P. Spencer, (Eds.), Oxford handbook of deaf studies, language and education (pp. 177-187).

Callanan, M. \& Oakes, L. (1992). Preschoolers' questions and parents' explanations. Cognitive Development, 7, 213-233.

Chi, M., DeLeeuw, N. Chiu, M. \& LaVancher, C. (1994). Eliciting self-explanations improves understanding. Cognitive Science, 18, 439-477. doi:10.1207/s15516709cog1803_3

Dunn, J. Brown, J., Slomsowski, C., Tesla, C. \& Youngblade, L. (1991). Young children's understanding of other people's feelings and beliefs. Child Development, 62, 1352-1366.

Dunn, J., \& Brown, J. R. (1993). Early conversations about causality: Content, pragmatics and developmental change. British Journal of Developmental Psychology, 11, 107-123. doi:10.1111/j.2044-835X.1993.tb00591.x

Fink, E., Begeer, S., Peterson, C., Slaughter, V., \& de Rosnay, M. (2015). Friendlessness and theory of mind: A prospective longitudinal study. British Journal of Developmental Psychology, 33, 1-17. doi:10.1111/bjdp.12060

Flavell, J. H. (2004). Theory-of-mind development: Retrospect and prospect. Merrill-Palmer Quarterly, 50(3), 274-290. doi:10.1353/mpq.2004.0018

Frazier, B. N., Gelman, S. A., \& Wellman, H. M. (2009). Preschoolers' search for explanatory information within adult-child conversation. Child Development, 80, 1592-1611. doi:10.1111/j.1467-8624.2009.01356.X

Frazier, B. N., Gelman, S. A., \& Wellman, H. M. (2016). Young children prefer and remember satisfying explanations. Journal of Cognition \& Development, 17, 718-736. doi:10.1080/15248372.2015.1098649

Goldin-Meadow, S., \& Mayberry, R. I. (2001). How do profoundly deaf children learn to read? Learning Disabilities Research \& Practice, 16(4), 222-229. doi:10.1111/0938-8982.00022

Gopnik, A., \& Wellman, H. M. (1994). The theory theory. In L. Hirschfeld \& S. Gelman (Eds.), Domain specificity in cognition and culture (pp. 257-293). New York: Cambridge University Press.

Gopnik, A., \& Wellman, H. M. (2012). Reconstructing constructivism: Causal models, Bayesian learning mechanisms, and the theory theory. Psychological Bulletin, 138, 1085-1108. doi:10.1037/a0028044

Happé, F., \& Frith, U. (1995). Theory of mind in autism. In E. Schopler, G. B. Mesibov, E. Schopler, G. B. Mesibov (Eds.), Learning and cognition in autism (pp. 177-197). New York, NY, US: Plenum Press. doi:10.1007/978-1-4899-1286-2_10 
Happé, F. E. (1995). The role of age and verbal ability in the theory of mind task performance of subjects with autism. Child Development, 66, 843-855. doi:10.2307/1131954

Harris, P.L. (2006). Social cognition. In W. Damon (Ed.), Handbook of child psychology (pp. 811857). New York: Wiley.

Hickling, A. K., \& Wellman, H. M. (2001). The emergence of children's causal explanations and theories: Evidence from everyday conversation. Developmental Psychology, 37, 668-683.

Hoemann, H. W. (1972). The development of communication skills in deaf and hearing children. Child Development, 43, 990-1003. doi:10.2307/1127649

Hood, L., \& Bloom, L. (1979). What, when, and how about why. Monographs of the Society for Research in Child Development, 44(6, Serial No. 181), 1-47. doi: 10.2307/1165989

Hughes, C. (2016). Theory of mind grows up. Journal of Experimental Child Psychology, 149, 1-5. doi: 10.1016/j.jecp.2016.01.017

Keil, F. (2006). Explanation and understanding. Annual Review of Psychology, 57, 227-254. doi: 101146/annurev.psych.57.102904.190100

Keil, F. \& Wilson, R. (2000). Explaining explanations. In F. Keil (Ed.) Explanation and cognition (pp 1-18), Boston, MA: MIT Press.

Kritzer, K. L. (2008). Family mediation of mathematically based concepts while engaged in a problem-solving activity with their young deaf children. Journal of Deaf Studies and Deaf Education, 13, 503-517.

Lalonde, C. E., \& Chandler, M. J. (1995). False belief understanding goes to school: On the socialemotional consequences of coming early or late to a first theory of mind. Cognition and Emotion, 9, 167-185. doi:10.1080/02699939508409007

Lecce, S., Bianco, F., Demicheli, P., \& Cavallini, E. (2014). Training preschoolers on first-order false belief understanding: Transfer on advanced ToM skills and metamemory. Child Development, 85 , 2404-2418. doi: 10.1111/cdev12267

Lecce, S., Caputi, M., \& Hughes, C. (2011). Does sensitivity to criticism mediate the relationship between theory of mind and academic achievement? Journal of Experimental Child Psychology, 110, 313-331. doi:10.1016/j.jecp.2011.04.011

Legare, C. H. (2012). Exploring explanation: Explaining inconsistent evidence informs exploratory, hypothesis-testing behavior in young children. Child Development, 83, 173-185. doi:10.1111/j.1467-8624.2011.01691.x

Legare, C. H., Gelman, S. A., \& Wellman, H. M. (2010). Inconsistency with prior knowledge triggers children's causal explanatory reasoning. Child Development, 81, 929-944. doi:10.1111/j.1467-8624.2010.01443.x 
Legare, C. H., Wellman, H. M., \& Gelman, S. A. (2009). Evidence for an explanation advantage in naive biological reasoning. Cognitive Psychology, 58, 177-194. doi:10.1016/ j.cogpsych.2008.06.002

Legare, C. H., Zhu, L. \& Wellman, H. M. (2013). Examining biological explanations in Chinese preschool children: A cross-cultural comparison. Journal of Cognition and Culture, 67-93.

Lohmann, H., \& Tomasello, M. (2003). The Role of Language in the Development of False Belief Understanding: A Training Study. Child Development, 74, 1130-1144. doi:10.1111/14678624.00597

Lombrozo, T. (2006). The structure and function of explanation. Trends in Cognitive Science, 10, 464-470. doi: 10.1016/j.tics.2006.08.004

Marschark, M., Spencer, P. E., Adams, J., \& Sapere, P. (2011). Evidence-based practice in educating deaf and hard-of-hearing children: Teaching to their cognitive strengths and needs. European Journal of Special Needs Education, 26, 3-16. doi: 10.1080/08856257.2011.543540

Meristo, M., Falkman, K., Hjelmquist, E., Tedoldi, M., Surian, L. \& Siegal, M. (2007). Language access and theory of mind reasoning: Evidence from deaf children in bilingual and oral environments. Developmental Psychology, 43, 1156-1169. doi: 10.1037/0012-1649.43.5.1156

Moeller, M. P. \& Schick, B. (2006). Relations between maternal input and theory of mind understanding in deaf children. Child Development, 73, 751-766.doi:10.1111/ j.14678624.20067703-0016

Miller, S.A. (2009). Children's understanding of second-order mental states. Psychological Bulletin, 135, 749-773.

NAATI (National Accreditation Authority for Translators and Interpreters Ltd.: 2011). About NAATI. Retrieved 22/09/2012 from http://www.naati.com.au

Paatsch, L. \& Toe, D. (2014). A comparison of pragmatic language abilities of children who are deaf or hard of hearing and their hearing peers. Journal of Deaf Studies and Deaf Education, 19, 1-19. doi 10.1093/deafed/ent03

Perret-Clermont, A.-N. (1980). Social interaction and cognitive development in children. London: Academic Press.

Peskin, J., \& Ardino, V. (2003). Representing the mental world in children's social Behavior: Playing hide-and-seek and keeping a secret. Social Development, 12, 496-512. doi:10.1111/14679507.00245

Peterson, C. C. (2009). Development of social-cognitive and communication skills in children born deaf. Scandinavian Journal of Psychology, 50, 475-483. doi: 10.1111/j.14679450.2009.00750.x 
Peterson, C.C. \& Peterson, J.L. (1990). Socio-cognitive conflict and spatial perspective-taking in deaf children. Journal of Applied Developmental Psychology, 11, 267-281. doi:10.1016/01933973(90)90010-H

Peterson, C., \& Slaughter, V. (2003). Opening windows into the mind: Mothers' preferences for mental state explanations and children's theory of mind. Cognitive Development, 18, 399-429. doi:10.1016/s0885-2014(03)00041-8

Peterson, C. C., \& Slaughter, V. P. (2006). Telling the story of theory of mind: Deaf and hearing children's narratives and mental state understanding. British Journal of Developmental Psychology, 24, 151-179. doi: 10.1348/026151005X60022

Peterson, C. C.. Wellman, H.M. \& Liu, D. (2005). Steps in theory of mind development among children with autism, deafness or typical development. Child Development, 76, 502-517. doi: 10.1111/j.1467-8624.2005.00859.x

Peterson, C. C., Wellman, H. M., \& Slaughter, V. (2012). The mind behind the message. Child Development, 83, 469-485. doi: 10.1111/j.1467-8624.2011.01728x

Peterson, C.C. \& Wellman, H. M. (in press). Longitudinal ToM development in children with and without ToM delay. Child Development.

Preisler, G., Tvingstedt, A.-L., \& Ahlström, M. (2005). Interviews with deaf children about their experiences using cochlear implants. American Annals of the Deaf, 150, 260-267. doi: 10.1353/aad.2005.0034

Rachford, D. \& Furth, H. (1986). Understanding friendship and social rules by deaf and hearing children. Journal of Applied Developmental Psychology, 7, 391-402.

Rhodes, M. \& Wellman, H.M. (2013). Constructing a new theory from old ideas and new evidence. Cognitive Science, 37, 592-604. doi:10.1111/cogs.12031

Ruffman, T., Slade, L., \& Crowe, E. (2002). The relation between children's and mothers' mental state language and theory-of-mind understanding. Child Development, 73, 734-751.doi: $10.1111 / 1467-8624.00435$

Schick, B., deVilliers, P., deVilliers, J. \& Hoffmeister, R. (2007). Language and theory of mind: A study of deaf children. Child Development, 78, 376- 396. doi: 10.1111/j.148624.2007.01004.

Schorr, E. A., Roth, F. P., \& Fox, N. A. (2008). A comparison of the speech and language skills of children with cochlear implants and children with normal hearing. Communication Disorders Quarterly, 29, 195-210. doi:10.1177/1525740108321217

Schult, C. A., \& Wellman, H. M. (1997). Explaining human movements and actions: Children's understanding of the limits of psychological explanation. Cognition, 62, 291-324. doi:10.1016/S0010-0277(96)00786-X 
Siegler, R. S. (1995). How does change occur: A microgenetic study of number conservation. Cognitive Psychology, 28, 225-273. doi:10.1006/cogp.1995.1006

Slaughter, V. \& De Rosnay, M. (2017). Theory of mind in context. Oxford, U.K.: Routledge.

Slaughter, V., Imuta, K., Peterson, C. C., \& Henry, J. D. (2015). Meta-analysis of theory of mind and peer popularity in the preschool and early school years. Child Development, 86, 1159-1174. doi:10.1111/cdev.12372

Slaughter, V., Peterson, C. C., \& Moore, C. (2013). I can talk you into it: Theory of mind and persuasion behavior in young children. Developmental Psychology, 49, 227-231. doi:10.1037/a0028280

Vaccari, C., \& Marschark, M. (1997). Communication between parents and deaf children: Implications for social-emotional development. Child Psychology \& Psychiatry \& Allied Disciplines, 38, 793-801. doi:10.1111/j.1469-7610.1997.tb01597.x

Walker, C. M., Lombrozo, T., Legare, C., Gopnik, A. (2014) Explaining prompts children to privilege inductively rich properties. Cognition, 133, 343-357. doi:10.1016/j.cognition.2014.07.008

Wellman, H.M. (2011). Reinvigorating explanations for the study of cognitive development. Child Development Perspectives, 5, 33-38. doi:10.1111/j.1750-8606.2010.00154.x

Wellman, H. M. (2014). Making minds: How theory of mind develops. New York: Oxford University Press.

Wellman, H. M., Fang, F., \& Peterson, C. C. (2011). Sequential progressions in a theory of mind scale: Longitudinal perspectives. Child Development, 82(3), 780-792. doi: 10.1111/j.14678624.2011.01583.x

Wellman, H. M., Cross, D., \& Watson, J. (2001). Meta-analysis of theory-of-mind development: The truth about false belief. Child Development, 72, 655-684. doi:10.1111/1467-8624.00304

Wellman, H. M., \& Liu, D. (2004). Scaling Theory-of-Mind tasks. Child Development, 75, 523541.doi: 10.1111/j.1467-8624.2004.00691.x

Wellman, H. M., \& Liu, D. (2007). Causal reasoning as informed by the early development of explanations. In A. Gopnik \& L. E. Schulz (Eds.), Causal learning: Psychology, philosophy, and computation (pp. 261-279). New York: Oxford University Press.

Wellman, H.M. \& Peterson, C. C. (2013). Deafness, thought bubbles and ToM development. Developmental Psychology, 49, 2357-2367. doi: 10.1037/a0032419

Wiig, E. H., Secord, W. A., \& Semel, E (1992). CELF-P : Clinical evaluation of language fundamentals--Preschool. San Antonio: Psychological Corp., Harcourt Brace Jovanovich. 
Wimmer, H. \& Mayringer, H. (1998). False belief understanding in young children: Explanations do not develop before predictions. International Journal of Behavioral Development, 22, 403422.

Wood, D. \& Wood, H. (1997). Communicating with children who are deaf: Pitfalls and possibilities. Language, Speech, and Hearing Services in Schools, 28, 348-354. doi: 10.1044/01611461.2804 .348

Table 1. Study 1's scoring of explanations along with examples from the children's transcripts

\begin{tabular}{|c|c|c|c|c|}
\hline $\begin{array}{c}\text { Explanation } \\
\text { type }\end{array}$ & Description & Examples from transcripts & $\begin{array}{c}\text { Strictly } \\
\text { Cognitive } \\
(S C) \text { score }\end{array}$ & $\begin{array}{l}\text { Broadly } \\
\text { Epistemic } \\
(B E) \text { score }\end{array}$ \\
\hline $\begin{array}{l}\text { Strictly } \\
\text { cognitive }\end{array}$ & $\begin{array}{l}\text { Cognitive verb(s) used } \\
\text { to relevantly and } \\
\text { causally explain the } \\
\text { false-belief-based action }\end{array}$ & $\begin{array}{l}\text { "She assumed it had bandaids } \\
\text { because of the picture" "She } \\
\text { thought it was her drink"; "She } \\
\text { forgot where she put her cup; } \\
\text { "She did not realize it was the } \\
\text { flowers", "She was not thinking } \\
\text { and grabbed the closest one"; }\end{array}$ & "Correct" & "Correct" \\
\hline $\begin{array}{l}\text { Non- } \\
\text { cognitive } \\
\text { epistemic }\end{array}$ & $\begin{array}{l}\text { Perception or intention } \\
\text { term(s) used to plausibly } \\
\text { and relevantly explain } \\
\text { the target action }\end{array}$ & $\begin{array}{l}\text { "She saw her glass there before"; } \\
\text { "She sees the bandaid picture"; } \\
\text { "She reads the label"; "She's on } \\
\text { the phone with her eyes shut"; } \\
\text { "She meant to take the other } \\
\text { one"; "She grabbed the wrong } \\
\text { one"; "She made a mistake" }\end{array}$ & "Incorrect" & "Correct" \\
\hline $\begin{array}{l}\text { Empty or } \\
\text { incomplete } \\
\text { (non- } \\
\text { credited) }\end{array}$ & $\begin{array}{l}\text { Explanations that fail to } \\
\text { clearly identify a } \\
\text { necessary causal } \\
\text { precondition for the } \\
\text { mistaken action, } \\
\text { including desire (D), } \\
\text { situational (S), non- } \\
\text { causal (NC), irrelevant }\end{array}$ & $\begin{array}{l}\text { "She wants chocolate sauce" (D); } \\
\text { "She's thirsty" (D); "She needs a } \\
\text { bandaid" (D); "Her glass was } \\
\text { there before" (S); "Someone } \\
\text { swapped the bottles" (S); "She } \\
\text { opens the bandaids and sees it's } \\
\text { empty" (NC); "She's a bad girl" } \\
\text { (I); "Flowers will die without }\end{array}$ & "Incorrect" & "Incorrect" \\
\hline
\end{tabular}



(I) and empty (E)
water" (I); “Don't know” (E)
explanations

Table 2. Mean scores on key Study 1 variables for children in each group

Variable Group 1: Deaf $(n=31) \quad$ Group 2: Hearing $(n=44)$

\begin{tabular}{rcc} 
Mean & 9.34 & 4.13 \\
Age (in years) & 1.92 & .46 \\
(range) & 5.83 to 12.42 & 3.08 to 5.00 \\
\hline
\end{tabular}

Total false belief prediction

(TFBP)

$\begin{array}{rcc}\text { Mean } & .68 & .80 \\ \text { SD } & 1.04 & .98 \\ \text { (range) } & 0 \text { to } 3 & 0 \text { to } 3\end{array}$

Total broadly epistemic (BE)

explanation

$\begin{array}{rcc}\text { Mean } & 2.13 & 1.39 \\ \mathrm{SD} & 1.09 & 1.24 \\ \text { (range) } & 0 \text { to } 3 & 0 \text { to } 3\end{array}$

Total strictly cognitive (SC)

explanation

$\begin{array}{rcc}\text { Mean } & 1.26 & .75 \\ \mathrm{SD} & 1.24 & .81 \\ \text { (range) } & 0 \text { to } 3 & 0 \text { to } 2\end{array}$

Language ability (out of 22)

Mean

17.68

17.03

SD

2.55

2.99

(range)

15 to 21

10 to 22

This article is protected by copyright. All rights reserved 
Table 3: Examples of Study 2 explanation training tasks with test questions and sample responses

\begin{tabular}{|c|c|c|}
\hline Explanation training tasks & Test question & Sample responses from transcripts \\
\hline $\begin{array}{l}\text { 1. A kitten chases ball of wool from under the bed to } \\
\text { under a chest of drawers. A boy who saw the ball under } \\
\text { the bed was out of the room when the kitten moved it } \\
\text { (pictured, changed location) }\end{array}$ & "Why is he looking under the bed?" & $\begin{array}{l}\text { "He thinks his cat is there" }(\mathrm{C}) \\
\text { "He did not see the kitten hiding the ball" (BE) } \\
\text { "He wants the ball" (W) } \\
\text { "Because he can't find his cat" (W) }\end{array}$ \\
\hline $\begin{array}{l}\text { 2. A gift is hidden under the big blue bed by A and, in } \\
\text { A's absence, it is moved by B who hides it under the } \\
\text { small pink bed (props, changed location) }\end{array}$ & $\begin{array}{l}\text { "Why is A going to the big blue } \\
\text { bed?" }\end{array}$ & $\begin{array}{l}\text { "He was not watching her when she put it there" (BE) } \\
\text { "He wants to wrap the present" (W) }\end{array}$ \\
\hline $\begin{array}{l}\text { 3. Boy pours a glass of desired drink (juice) and puts it } \\
\text { just behind him on desk; Mum silently moves the juice } \\
\text { far side of the table and puts an undesired drink (water) } \\
\text { where the juice was (pictured, changed location) }\end{array}$ & "Why is boy drinking the water?" & $\begin{array}{l}\text { "He doesn't know Mum moved the water there" (C) } \\
\text { "Because that's not orange juice" (W) } \\
\text { "Because Mum swapped the drinks around" (W) }\end{array}$ \\
\hline $\begin{array}{l}\text { 4. Puzzle pieces are moved from their commercial box } \\
\text { (pictorially labeled) to a plain box. Then a naïve doll } \\
\text { arrives with a partly assembled puzzle wanting a } \\
\text { missing piece (props, misleading container) }\end{array}$ & $\begin{array}{l}\text { "Why does she look here [pointing at } \\
\text { pictorially labeled] box for her } \\
\text { dinosaur puzzle?" }\end{array}$ & $\begin{array}{l}\text { "She sees the dinosaur [label] so she thinks it's in } \\
\text { there" (C) } \\
\text { "She does not know the puzzle is in the other box" (C) } \\
\text { "She loves doing puzzles" (W) }\end{array}$ \\
\hline
\end{tabular}


5. Doll with a bleeding knee marches towards a pictorially labeled bandaid box. (Only the child knows

it is empty and that bandaids are in blue box across the desk) (props, misleading container)
"Why is she going to this box

[pointing]"?
"Cos it looks like bandaids should be in that kind of box" (BE)

"She needs a bandaid" (W)

Notes: $\mathrm{C}=$ correct via $\mathrm{SC}$ (and $\mathrm{BE}$ ) scoring; $\mathrm{BE}=$ correct only via $\mathrm{BE}$ scoring; $\mathrm{W}=$ wrong (zero score)

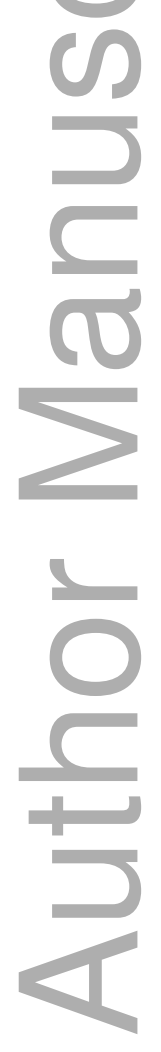

This article is protected by copyright. All rights reserved 
Table 4. Performance on Study 2 post-test measures and language ability

\begin{tabular}{lllll} 
& Group & $\mathrm{N}$ & Mean & (SD) \\
\hline Immediate Post-test TFBP4 & Training & 11 & 2.27 & $(1.42)$ \\
(max. 4) & Control & 12 & .58 & $(.793)$ \\
Immediate Post-test KA & Training & 11 & .64 & $(.50)$ \\
(max. 1) & Control & 12 & .25 & $(.45)$ \\
Immediate Post-test TFBP6 & Training & 11 & 3.45 & $(1.92)$ \\
(max. 6) & Control & 12 & .92 & $(1.23)$ \\
Delay Post-test TFBP4 & Training & 11 & 2.82 & $(1.47)$ \\
(max. 4) & Control & 14 & .83 & $(.84)$ \\
Delay Post-test KA & Training & 11 & .73 & $(.47)$ \\
(max. 1) & Control & 14 & .50 & $(.52)$ \\
Language Ability & Training & 11 & 14.82 & $(3.00)$ \\
(max. 22) & Control & 14 & 15.00 & $(3.26)$
\end{tabular}

Figure 1. False belief prediction (percent correct) by ToM-Training and Non-ToM-Control groups at pretest, immediate posttest and delayed posttest

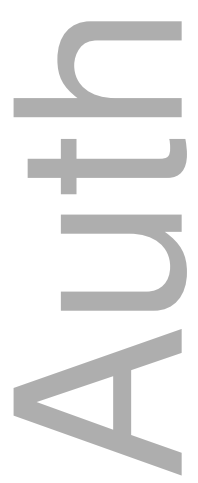


Figure 1

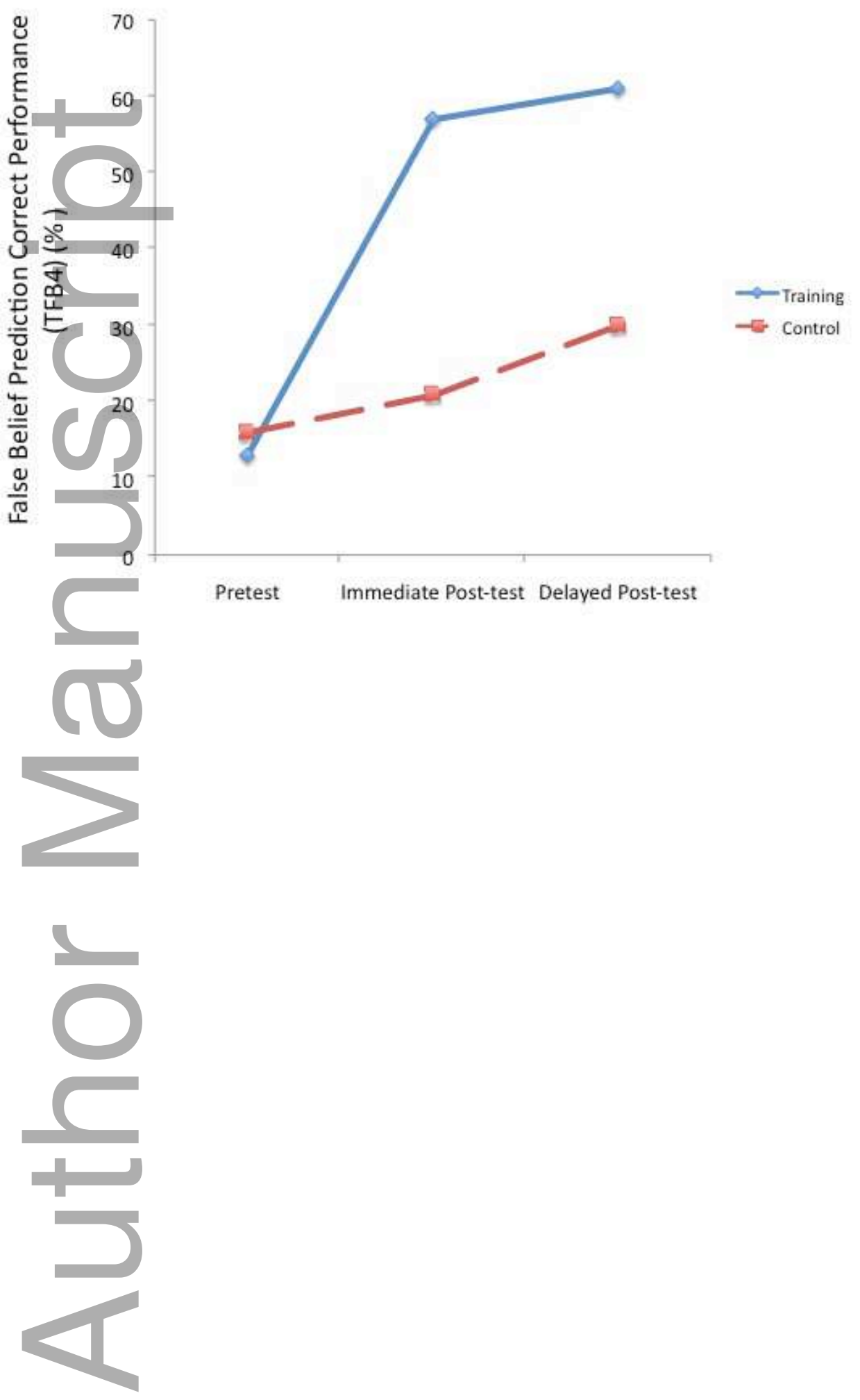

